\title{
LEITURA FINITA DE UM TEXTO INFINITO: \\ Galáxias de Haroldo de Campos \\ Inês Oseki-Dépré
}

* (Sobre isso, cf. BENJAMIN, Walter. "La tâche du traducteur". In: Mythe et violence. Paris: Denoel, 1971. MESCHONNIC, Henry. Poétique du traduire. Paris: Verdier, 1999.)

\section{Introdução}

A análise que se segue tem como foco um fragmento de $G A$ LAXIAS (no 45), de Haroldo de Campos, extraído de sua tradução francesa, que tomaremos aqui como um texto original.*

Seremos breves na primeira parte desta exposição, que tenta demonstrar que o aspecto meteórico do texto serve para melhor dissimular sua organização sintática e poética, condição prévia de toda tradução. A análise será concisa em virtude de já ter sido realizada na versão francesa e pelo fato de os elementos comuns já terem sido transpostos de uma língua para a outra. Os elementos específicos serão examinados mais adiante.

Em um segundo momento, abordaremos a questão da intertextualidade - latente no fragmento - como saber literário, que é o ponto de interesse do nosso estudo. Essa intertextualidade se remete ao passado e ao futuro, conjugando a tradição homérica à poesia em transformação, por meio da tradução e da paródia.

Em suma, trata-se de mostrar que se o texto traz em si um saber sobre a literatura, ele comporta outros elementos cognitivos a serem decodificados no momento de sua recepção. Esse momento da análise leva em consideração as duas línguas em questão e revela a aporia da tradução (Derrida): com efeito, a despeito de sua impossibilidade primeira ("a tradução é impossível”), a tradução confirma seu caráter essencial, transformando seu autor e seu leitor (e seu tradutor). Para concluir, abordaremos a questão de saber em que medida a escrita haroldiana é barroca e, por outro lado, se seria possível ver nela uma reativação da epopeia como origem da poesia. 


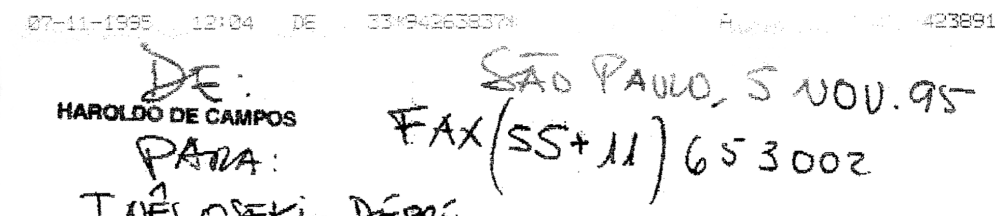

INÊS OSEKI- DEPRE

Fratae

FAX $00+33+94263837$

MINHA CARA INES:

acapoi de dever todos os fragmentos GAláIICOS QUE VOCE ME ENVIOU (NA Minita DELASAO, FALTAM ALGUKO POUCOS, QUE - SUPONHD AINDA NATO ESTARÁ TRABUzidÓS). REVI TAMPJEM O FINLSMUNDO, QuE - PARECE-ME - DESULTOU bEM

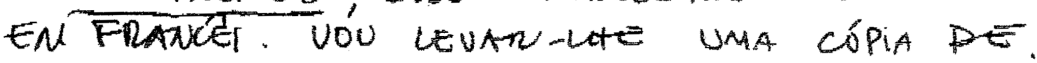
YUGUEN, O caderno de TOEMAS que EICREUi DURANTE MiNHa ESTABA No JaTÁ (O PIZA PEDiU-ME UM texto para llosthar; creí que

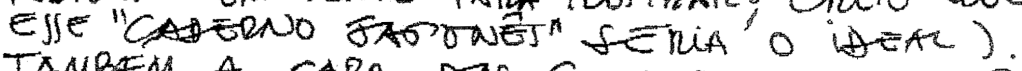
tambrem a capa das gautzies podzria ficar A CARGO DO PIZA, CREIO.

pego-lhe qué traga a ivry-tor-geine o tota

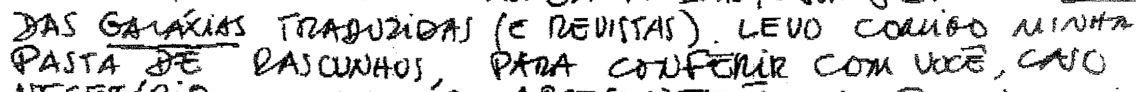

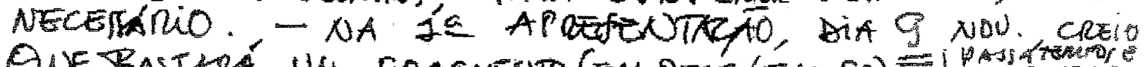

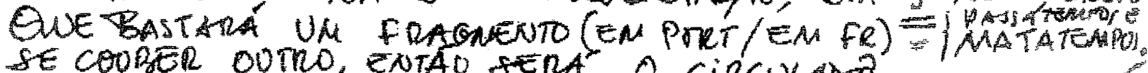
SE coober ouTro, ENTAO sera O circulabo.

DiA 9, 5a FEIRA, Nor EREMOS EM IVRY, EM TOWNO 16:00. CASO HAJA ALGWNA NOVIOABE OU AOO

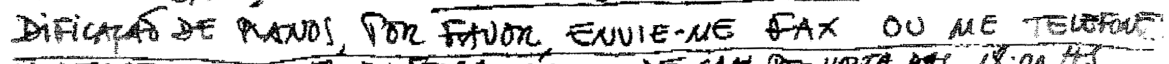

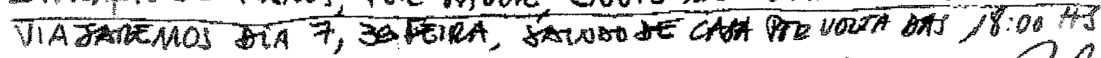

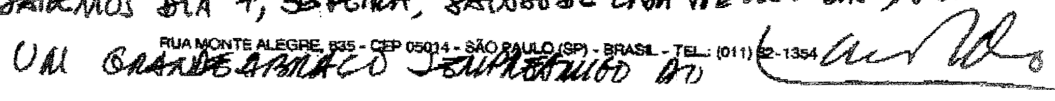

Carta de Haroldo de Campos a Inês Oseki-Dépré. 


\section{O texto original}

mais uma vez junto ao mar polifluxbórboro polivozbárbaro polúphloisbos polyfízzyboisterous weitaufrauschend fluctissonante esse mar esse mar esse mar esse martexto por quem os signos dobram marujando num estuário de papel num mortuário num monstruário de papel múrmur-rúmor-remurmunhante escribalbuciando você converte estes signos-sinos num dobre numa dobra de finados enfim nada de papel estes signos você os ergue contra tuas ruínas ou tuas ruínas contra estes signos balbucilente sololetreando a sóbrio neste eldorido feldorado latinoamargo tua barrouca mortopopéia ibericaña na primeira posição do amor ela ergue os joelhos quase êmbolos castanho-lisos e um vagido sussubmisso começa a escorrer como saliva e a mesma castanho-lisa mão retira agora uma lauda datiloscrita da máquinade-escrever quando a saliva já remora na memória o seu ponto saturado de perfume apenas a lembrança de um ter-sido que não foi ou foi não-sendo ou sido é-se pois os signos dobram por este texto que subsume os contextos e os produz como figuras de escrita uma polipalavra contendo todo o rumor do mar uma palavra-búzio que homero soprou e que se deixa transoprar através do sucessivo escarcéu de traduções encadeadas vogais vogando contra o encapelo móvel das consoantes assim também viagem microviagem num livro-de-viagens na segunda posição ela está boca-à-terra e um fauno varicoso e senil a empala todocoberto de racimos de uva e revoado por vespas raivecidas que prelibam o mel mascavo minado das regiões escuras dizer que essas palavras convivem no mesmo mar de sargaços da memória é dizer que a linguagem é uma água de barrela uma borra de baixela e que a tela se entretela à tela e tudo se entremela na mesma charada charamela de charonhas carantonhas ou carantelas que trelam e taramelam o pesardelo de um babuíno bêbedo e seus palradisos pastificiosos terrorescendo os festins floriletos pois a linguagem e lavagem é resíduo de drenagem é ressaca e é cloaca e nessa noite nócua é que está sua mensagem nesse publiexposto putriexposto palincesto de todos os passíveis excessos de linguagem abcesso obsesso e houve também a estória daquele alemão que queria aprender o francês por um método rápido assimil de sua invenção e que aprendia uma palavra por dia un mot par jour zept mots chaque zemaine e ao cabo de um mês e ao fim de seis meses e ao fim e ao cabo de um ano tinha já tudo sabido trezentas e sessenta e cinco palavras sabidas tout reglé en ordre bien classé là voui là dans mon cul la kulturra aveva raggione quello tedesco e a civilização quero que se danem e é sarro e barro e escarro e amaro isto que fermenta no mais profundo fundo do pélago-linguagem onde o livro faz-se pois não se trata aqui de um livro-rosa para almicândidas e demidonzelas ohfélias nem de um best-seller fimfeliz para amadores de amordorflor mas sim de um nigrolivro um pesteseller um horrídeodigesto de leitura apfelstúrdia para vagamundos e gatopingados e sesquipedantes e sestralunáticos abstractores enfim quintessentes do elixir caximônico em cartapáceos

* (CAMPOS, Haroldo de. Galáxias. São Paulo: Editora Ex-libris, 1984.) 


\section{A tradução}

une fois de plus vers la mer polifluxborborante polivocobarbare polúphloisbos polyfizzyboisterous weitaufrauschend fluctissonante vers la mer vers la mer mertexte pour qui consonnent les glas cette mer matelottante dans son extuaire de papier mortuairemonstruaire de papier murmur-rumeur-ruante toi scribalbutiant tu convertis ces signes qui sonnent en chant en plein chant de jourdesmorts funiveresse du papier ces signes tu les dresses contre tes ruines ou tes ruines contre ces signes-sons balbusilencieux sololettriste syllabant dans ton eldouloureux fieldorado latinoamer ta barauque mortépopée ibericaña dans la première position de l'amour elle dresse les genoux quasi-gonds d'une flexion châtain-lisse et son vagissement soussoumis s'écoule en salive et la même châtain-lisse main retire maintenant un texte dactyloécrit de la machineà-écrire quand la salive déjà retrace sa trace jusqu'à son point de saturation de parfum à peine le souvenir d'un avoir-été qui ne fut pas ou fut sans être car les glas consonnent pour ce texte qui subsume les contextes et les produit comme figures d'écriture une polyparole contenant toute la rumeur de la mer une parole-buccin qu'homère souffla et qui se laisse transsouffler à travers le successif tintamarre de traductions enchaînées voyelles vogantes contre le jaillissement mobile des consonnes ainsi aussi voyage revoyage le long d'un livre-de-voyages dans la deuxième position elle est bouche-à-terre et un faune variqueux et sénile l'empale tout couvert de grappes de raisin et envoilé de guêpes enragées qui avantgoûtent le miel adultéré miné des régions obscures dire que ces mots cohabitent dans la même mer des sargasses de la mémoire c'est dire que le langage est une eau de lessive une lie de vaisselle et que la toile s'entretoile à la toile et tout s'entremêle dans la même charade chalumeuse des trognes des charognes qui trichent et trébuchent le cauchemasardeux d'un babouin ivrogne et ses parladits pâteux terrorescents les festins-florilèges car le langage est lavage et résidu de drainage est ressac et est cloaque et dans cette nuit nuisible réside son message dans ce publiexposé putriexposé palimpseste de tous les passibles excès de langage abcès obsexionné et il y eut aussi l'histoire de cet allemand qui voulait apprendre la français par une méthode rapide assimil de son invention et qui apprenait une parole par jour un mot par jour zept mots chaque zemaine et au bout d'un mois et au terme de six mois et à la fin et au bout d'un an avait déjà tout appris trois cent soixante-cinq mots sus tout réglé en ordre bien classé là oui là dans mon cul la kulturra aveva raggione quello tedesco et la civilisation je veux qu'elles se fassent foutre et est boue et glu et déchet et amer ce qui bouillonne dans le fondprofond du pélagos-langage où le livre se livre car il ne s'agit pas ici d'un livre-rose pour d'âmes-candides et demipucelles orphélyriques ni d' un best-seller finheureuse pour amateurs d'amourdouleurfleur mais bien d'un nigrolivre un pesteseller un horreader-digest de lecture apfelstourdissante pour vagamondes et loups-garous et sesquipédants et sestralunatiques abstracteurs enfin quintessents de l'elixir de la sacrécaboche en mille feuillets galactiques dans la troisième position elle est signe et saigne elle est lasse et glisse et les glas résonnent* *(CAMPOS, Haroldo de.
Haroldo de Campos, une
anthologie. Apresenta-
ção e tradução de Inês
Oseki-Dépré. Paris: Al
Dante, 2005) 
* (CAMPOS, Haroldo de. Galáxias. São Paulo: Editora Ex-libris, 1984.)

* (ROUBAUD, Jacques. "Quelques thèses sur la poétique". Change 6. Seuil, Paris, 1970: 19.)
A leitura

No momento da publicação integral de Galáxias, em 1984, Haroldo de Campos fez a seguinte apresentação: "O formante inicial de Galáxias (início/ fim) é de 1963, o terminal de 1976.” Tratase de um "texto imaginado no limite extremo da poesia e da prosa, pulsão bioescritural em expansão galáctica entre estes dois formantes cambiáveis e cambiantes", e tendo por ímã temático a viagem como livro ou o livro como viagem, e por isso mesmo entendido também como um "livro de ensaios, hoje retrospectivamente eu tenderia a vê-lo como uma insinuação épica que se resolveu numa epifânica.”*

Para proceder à análise do texto escolhido, o fragmento 45, impõem-se duas considerações. A primeira refere-se à apresentação do texto, bastante homogênea, com o número de linhas equivalente ao dos outros fragmentos - entre 40 e 50 linhas em cada página -, ausência de pontuação e de letras maiúsculas. A segunda, tendo em conta o fato de que nós o traduzimos, diz respeito à presença simultânea de um princípio de organização - que o situa imediatamente no domínio do Texto enquanto objeto semiótico - e de um princípio de desconstrução - que o situa, como quer o próprio Haroldo de Campos, no domínio do Texto pós-utópico, cuja definição estabeleceremos mais à frente.

Primeira parte: O texto, memória e código da língua

Em uma primeira parte, tentaremos mostrar, de forma breve, em que medida o texto codifica, segundo os termos de Jacques Roubaud, "o fato de que toda língua é construída com o auxílio de elementos sonoros sem significado cuja concatenação faz aparecer, na frase, o sentido"), ${ }^{*}$ e de que maneira o fragmento apresentado é, e não é, um poema em versos livres. Em outros termos, em que medida esse poema é ao mesmo tempo memória e devir da língua. Para realizar tal tarefa, buscaremos suporte na teoria de Jakobson. ${ }^{1}$

Jakobson formula uma definição complexa do texto literário e, em particular, do texto poético, que pode ser resumida a partir dos três pontos que o caracterizam:

\footnotetext{
${ }^{1}$ A "teoria" de Jakobson deriva de sua definição de função poética (Essais de Linguistique Générale. Paris: Gallimard, 1970), e de suas inúmeras análises do texto literário.
} 
a) o "trabalho" sobre a matéria significante;

b) a recorrência de equivalências paradigmáticas agindo sobre o eixo sintagmático (equivalências forma/ sentido do tipo similar ou dissimilar);

c) a sobrecodificação paralelística, ou seja, a sobredeterminação das estruturas recorrentes agindo sobre os diversos níveis em que elas se realizam.

É, portanto, poético o texto que satisfaz a essas três condições, e é nesse sentido que ele se presta à análise semiótica, cujo objeto, a literariedade, constitui a invariante que se encontra em qualquer literatura, que é assim formalmente definida.

Sem negar o valor dessa teoria, que é a primeira a permitir que se efetue um salto qualitativo no domínio da teoria literária, a questão que hoje se impóe ao semioticista vai mais longe e diz respeito ao problema da escrita; em outras palavras, refere-se ao problema da relação do sujeito-escritor com o Texto (e não mais do Autor investido de poderes extraordinários da visão romântica e pós-romântica) e, de maneira análoga, da relação do Texto com o contexto, com o mundo.

A leitura analítica do texto de Haroldo de Campos que nos propomos realizar vale-se de dois aspectos dessa questão:

Análise do fragmento

A primeira observação que faremos sobre o fragmento a ser analisado diz respeito à não conformidade às regras formais do texto poético tradicional. Assim, é impossível classificá-lo a priori entre as formas conhecidas.

$\mathrm{O}$ fato de o texto não possuir forma fixa não nos impede - na medida em que o consideramos como um objeto semiótico - de traçar as linhas provisórias que delimitam suas unidades. Assim sendo, mesmo sabendo que a unidade linha, que resulta da distribuição intencional dos "versos" na página, está submetida a um princípio rítmico, ${ }^{2}$ utilizaremos o critério sintático. As unidades assim demarcadas permitem examinar ao mesmo tempo o texto original e sua tradução, já que é pelo léxico e pela prosódia que encontramos seus elementos diferenciais, que serão analisados mais à fren-

\footnotetext{
2 "O único traço formal que caracteriza o verso livre como poesia é a construção do parágrafo”. ROUBAUD, Jacques. op. cit.: 20.
} 
te. Além disso, se a linha é a unidade formal do poema, é a frase que permite traduzi-lo.

É evidente que não nos furtaremos a propor mais adiante uma visão sintética do conjunto. Vale acrescentar que se nossa leitura/ análise toma a sintaxe ${ }^{3}$ como ponto de partida, ela não exclui, contudo, os outros parâmetros que constituirão a literariedade do Texto escolhido (fonossemântica).

Nossa segunda observação pretende precisar o modo como procederemos para efetuar a análise. Esta se limitará, em função dos limites desta exposição, à primeira frase complexa do Texto, que será

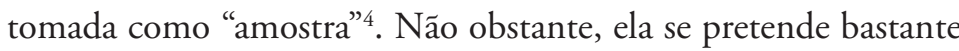
simples, podendo ser tomada por uma análise do tipo tradicional, recorrendo, em determinados momentos, a certas contribuições linguísticas propostas por Nicolas Ruwet em suas análises.

\section{PRIMEIRO PERÍODO (P.I):}

Oração principal: "uma vez mais junto ao mar (...) você con-

*(linhas 1-5)

*(linhas 6-8) verte estes signos-sinos num dobre" ("une fois de plus... tu convertis les signes qui sonnent en chant...")*

Oração coordenada: "você os ergue contra tuas ruínas...” ("tu les dresses contre tes ruines...")*

Apesar de serem quantitativamente distintas (5 linhas e 3 linhas), essas duas oraçōes podem ser consideradas como paralelas, porque têm em comum o sujeito (" $t u$ ") e o complemento ("signes": "ces signes", "les"), além de os dois verbos serem transitivos ("convertis", "dresses") e se apresentarem no mesmo tempo (presente do indicativo).

Examinando as duas orações, percebemos que a segunda pode ser considerada uma expansão da primeira por meio da substituição "ces signes" - "les", e podemos representá-las pelo esquema:

Primeira Oração $=$ exposição - Segunda Oração $=$ expansão.

Acrescentemos a isso o fato de que o complemento da oração principal - "signes" ("qui sonnent") - está ligado à oração anterior intercalada - "pour qui consonnent les glas" ("sonnent") "consonnent") ${ }^{5}$. Por outro lado, a expansão pode ser desdobrada

\footnotetext{
${ }^{3}$ Aliás, a estrutura sintática é o elemento comum às duas línguas, devido, por um lado, à sua origem latina comum e, por outro, ao caráter altamente elíptico da sintaxe do poema. "O poema, aqui, é frase." Ibidem.

${ }^{4} \mathrm{~A}$ análise da amostra poderia evidentemente prosseguir.

${ }^{5}$ Em português: "dobram", "sinos" (substantivo traduzido por um verbo).
} 
em duas orações (unidas pela conjunção "ou”), em que a segunda se caracteriza pela presença de um núcleo implícito ("tu dresses tes ruines contre tes signes").

Uma vez destacada a estrutura sintática desse primeiro período (P.I), que constitui, a nosso ver, a primeira parte do texto (a matriz), tentemos observar em que medida a organização do núcleo é sobredeterminada por suborganizações prosódicas ou fônicas do texto.

$\begin{array}{llllllllllll}\text { A } & \text { B } & \text { C } & \text { D } & \text { E } & \text { F } & \text { G } & \text { H } & \text { I } & \text { J } & \text { K }\end{array}$

escribalbuciando você converte estes signos-sinos num dobre numa dobra de finados enfim nada de papel você ergue estes signos/os contra tuas ruínas tuas ruínas contra esses signos

ou

balbuciliente tua barrouca neste eldorido sololetrando a mortopopéia feldorado sóbrio ibericaña latinoamargo

toi scribalbutiando tu convertis ces signes qui sonnent en chant

$$
\begin{gathered}
\text { en plein chant des } \\
\text { jourdemorts } \\
\text { funivresse } \\
\text { du papier } \\
\text { jeudemots }
\end{gathered}
$$

ces signes

tu dresses

$$
\text { les }
$$

contres tes ruines

ou

tes ruines

contre ces

signes-sons

balbusilencieux

sololettriste 
De saída, notamos que ao paralelismo sintático corresponde um paralelismo prosódico, ainda que assimétrico, sobretudo em francês. A prosódia é aqui marcada por recorrências rítmicas e sonoras. Com efeito, à primeira forma no gerúndio - "scribalbutiant" ("escribalbuciando") -, opõe-se uma forma transitiva - "syllabant ta..." ("sololetreando a...”) -, que se encontra, além disso, reforçada pelo sintagma determinante "balbusilencieux sololettriste" ("balbucilente”, com deslocamento do verbo neológico para o adjetivo), e é alongada pelo complemento circunstancial de lugar "dans ton eldouloureux fieldorado latinoamer" ("neste eldorido feldourado latinoamargo").

As duas formas no gerúndio em questão (C) são constituídas de palavras-valises que contêm a mesma substância sêmica:

scrib+ (b) albutiant

syllab+ant (balbu+silencieux/solo+lettriste)

Ou seja, elas remetem ao ato de escrever e de ler de maneira aplicada (maior dificuldade).

Já evocamos as classes (D) e (E), que não oferecem particularidades. A classe (F) oferece um falso paralelismo duplo: "ces", "ces" / "tes", " $t a$ " - mas o segundo possessivo no singular indica uma oposição ao plural da primeira forma. Na realidade, "ces" e "tes" encontram-se distribuídos de maneira complementar, e " $t a$ " introduz uma assimetria, apresentando-se como o determinante do complemento de "syllabant", e não de "dresses". Além disso, "ces" está sempre seguido de "signes" e "tes" de "ruines", enquanto " $t a$ " precede "morépopée".

As três unidades de $(G)$ também são palavras-valises: ba+rauquel morto+(é)popéel iberica(na). É também na classe $(\mathrm{G})$ que são encontrados os complementos de (E). Entretanto, enquanto em sua primeira ocorrência, "signes" (objeto direto) encontra-se determinado por uma oração relativa - "qui sonnent" -, no segundo caso, o termo aparece anteposto ao verbo e é substituído pelo pronome "les". Por outro lado, a classe $(G)$ está em relação com a classe (I) no jogo de permuta entre "signes" X "ruines" / "ruines" $\mathrm{X}$ “signes-sons". 
A esse propósito, podemos verificar também a semelhança (fonossemântica) entre:

$\begin{array}{lll}\text { "eldouloureux } & \text { fieldorado } & \text { latinoamer" } \\ \text { "baranque } & \text { mortépopée } & \text { ibéricaña" }\end{array}$

Tais termos se apresentam em relação de equivalência sintagmática, estando as duas classes precedidas do possessivo singular (“ta" / "ton" (J)).

\section{Escansão do conjunto}

Propomos agora nossa escansão do texto em suas partes constitutivas visando à harmonização dos diversos níveis encontrados no texto literário.

Não é inútil insistir no fato de que nossa divisão, aparentemente arbitrária - uma vez que nada impediria de considerar o texto como um único e longo período ${ }^{6}$-, justifica-se por razões metodológicas, na medida em que possui a vantagem de ressaltar no texto a presença de unidades poéticas recorrentes em todos os níveis.

Assim, o texto pode ser dividido em quatro períodos:

1(a) "uma vez mais junto ao mar... você converte estes signos... papel"* "une fois de plus vers la mer...tu convertis ces signes... du papier"*

1(b) "estes signos você os ergue... ibericaña"* "ces signes tu les dresses... ibericana"*

2(a) "na primeira posição do amor... ou foi não sendo"* “dans la première position de l'amour... ou fut-sans-être"*

2(b) "pois os signos dobram... num livro de viagens"* "car les glas consonnent... le long d'un livre-de-voyages"*

3(a) "na segunda posição... regiōes escuras"* "dans la deuxième position... des régions obscures"*

3(b) "dizer que essas palavras... os festins floriletos"* "dire que ces mots coalisent... les festins florilèges"*

3(c) "pois a linguagem é lavagem... abcesso obsesso"* "car le langage est lavage... abcès obsexionnê"*

3(d) "e houve também... quello tedesco"* "et il y eut aussi l'histoire... ce tudesque-là"*

3(f) "pois não se trata... cartapáceos galácticos”* “car il ne s'agit pas ici... en mille-feuillets galactiques"*

* (linhas 1-6)

*(linhas 1-6)

* (linhas 6-9)

* (linhas 6-9)

*(linhas 9-13)

* (linhas 9-15)

* (linhas 15-19)

* (linhas 15-20)

* (linhas 20-22

* (linhas 20-23)

* (linhas 20-27)

* (linhas 23-29)

* (linhas 27-30)

* (linhas 29-32)

* (linhas 30-36)

* (linhas 32-38)

* (linhas 36-43)

* (linhas 40-46)

\footnotetext{
${ }^{6} \mathrm{O}$ que confirmaria, se necessário, a ausência de pontuação.
} 
4 "na terceira posição ela... e por quem dobra"* "dans la troisième position... et les glas résonnent"*

Embora o critério que nos permite dividir o texto em quatro períodos seja, como já dissemos, o critério sintático (clássico), pensamos que, do ponto de vista semântico, seria interessante considerar as cinco partes seguintes:

P.I: Introito (matriz)

P.II: Primeiro movimento

P.III: Segundo movimento (a, b, c)

Parêntese ou terceiro movimento $(\mathrm{d}, \mathrm{e}, \mathrm{f})$

P.IV: Final do quarto movimento

Estamos, portanto, lidando com estruturas sobrepostas. Pois se, do ponto de vista sintático, cada parte se caracteriza pela presença inicial de um complemento circunstancial de lugar:

"une fois de plus vers la mer" (I)

"dans la première position" (II)

"dans la deuxième position" (III)

"dans la troisième position" (IV)

por outro lado, o Parêntese parece desempenhar uma função semântica distinta (inclusão-exclusão do conjunto), sem, contudo, manter essa marca formal.

Em contrapartida, o Introito se opõe ao conjunto do texto pela ausência de sequência explicativa introduzida pela conjunção "car", que aparece no Parêntese.

"car les glas consonnent" (II)

"car le langage est lavage" (III)

"car il ne s'agit pas ici d'un livre-rose" (III).

Os níveis sintático e semântico apresentam assim alguns descompassos significativos da estrutura em contraponto ao conjunto do Texto. O quarto movimento (Final), interrompido, não oferece uma explicativa explícita, enquanto o segundo (P.III), apresenta duas. Conforme mostraremos a seguir, o motivo dessas três oraçôes é, de uma maneira cada vez mais metalinguística, o livro, a linguagem e os signos.

Da mesma forma, do ponto de vista sintático, podemos observar que as três orações que têm "elle" como sujeito se comportam de maneira análoga: complemento circunstancial de lugar + núcleo + coordenada ("et") + coordenada ("et"):

Elle + verbo (presente do indicativo) 
"elle dresse les genoux" + "et son vagissement... sécoule"

"et la... main retire... un texte"

(ela ergue os joelhos + e um vagido... começa a escorrer)

(e a... mão retira... urna lauda)

"elle est bouche-à-terre" + "et un faune... l'empale"

(ela está boca à terra + e um fauno... a empala)

"et survolé..."

(e revoado...)

"elle est signe + et saigne"

$(\text { ela é signo }+ \text { e sino })^{7}$

+ "et les glas résonnent"

(+ e os sinos dobram)

"elle est lasse + et glisse"

A última oração ("elle"), que não possui sequência explicativa, oferece, "em compensação", um exemplo de desdobramento paralelístico ainda mais rico pelo fato de se realizar por meio de equivalências fonoprosódicas (atributo/ predicado) com uma configuração quiasmática ao nível das vogais ("signe"/ "saigne"/ "lasse"/ "glisse").

Já do ponto de vista lexical, podemos observar a transformação do verbo de ação ("dresse") em verbo de ligação ("est"), até o apagamento do sujeito "elle".

Nos três casos, as orações coordenadas não têm "elle" como sujeito, e passa-se da metonímia ("vagissement", vagido) ao Outro, agente exterior, num primeiro momento metonímico (“à main", a mão), em seguida mitológico (“un faune”, um fauno), e, por fim, metalinguístico ("les glas", os sinos). De forma análoga, as oraçôes relativas não se remetem jamais a "elle" enquanto antecedente.

É na segunda ocorrência de "elle" (P.III) que encontramos o maior número de orações, distribuídas em duas tópicas, que poderíamos chamar de "interior" e "exterior". Com efeito, encontramos respectivamente em cada uma delas uma reflexão metalinguística:

"dire que ces mots...c'est dire...et que" (dizer que...dizer que), com uma estrutura verbal "infinitiva" e um parêntese anedótico - inserção da narrativa no discurso, com seu sistema acabado do

\footnotetext{
${ }^{7}$ Em português: ela é signo e sino, substituído aqui por sangue em virtude "de contaminação semântica" (deslizamento do significado).

${ }^{8}$ A estrutura sintática é a mesma em português: pois, pois, pois (car), ela (elle). O último verso é acrescentado em função do ritmo.
} 
ponto de vista do sujeito, dos tempos verbais e dos dêiticos - introduzido de maneira impessoal:

"et il y eut aussi l'histoire..." (e houve também a história...)

Seria quase supérfluo observar a sobredeterminação desse recorte pela estruturação do nível prosódico (ritmo e sonoridades). Isso porque à regularidade silábica subjacente corresponde de fato uma grande quantidade de assonâncias, aliteraçôes e até paronomásias, sobre as vogais [i] (lisos, vagido, sussubmisso, saliva, lisa, retira, datiloscrita, sido, signos, escrita), $[\mathrm{e}]$ e $[\varepsilon]$ (ela, ergue, joelhos, êmbolos, começa, escorrer, escrever), no texto em português, $\mathrm{e}$, no texto em francês, sobre as consoantes /s/ (dresse, flexion, lisse, texte, salive, retrace, trace, saturation, souvenir, sans, consonnent, subsume, contexte) e /r/ (dresse, retire, dactyloécrit, écrire, retrace, trace, parfum, produit, écriture, polyparole etc). ${ }^{9}$

\section{O Parêntese}

$\mathrm{Na}$ passagem funcionalmente distinta que chamamos de $\mathrm{Pa}$ rêntese, os paralelismos se apresentam não sob a forma de sucessão sintagmática mas, mais nitidamente, sob a forma de paradigma:

"une parole par jour" (uma palavra por dia)

"un mot par jour"

"sept mots chaque semaine"

"et au bout d'un mois" (e ao cabo de um mês)

"et au terme de six mois" (e ao fim de seis meses)

"et à la fin et au bout d'un an". (e ao fim e ao cabo de um ano)

O paralelismo sintático também se apresenta sob a forma de relativas:

"qui voulait" / "et qui apprenait" / (que queria /e que aprendia)

Podemos somar a esses exemplos as rimas imperfeitas (assonâncias) em francês:

"boue" / "glu" (sarro e barro e escarro e amaro)

"déchet" / "amer"

"fondprofond" e "le livre se livre" (profundo fundo/ o livro faz-

se)

As recorrências apresentam-se sob a forma de palavras compostas: "livre-rose", "demipucelles orphélyriques", "âmes-candides",

\footnotetext{
9 Segundo o princípio da "compensação".
} 
"best-seller", "finheureuse", "nigro-livre", "pesteseller", "horreader-digeste"; e de palavras-valises: "vagamondes", "sesquipédants", "apfesltourdissant", "quintessents", "sacrecaboche" etc, em um processo de enumeração amplificante.

O interesse dessa escansão sintático-semântica reside no fato de possibilitar uma melhor apreensão dos paralelismos formais entre as grandes (e as pequenas) unidades sintáticas do texto e, por conseguinte, do trabalho de codificação efetuado pelo poeta, que produz, dissimulando-as, suas unidades sobredeterminadas.

Assim, podemos destacar as equivalências que asseguram a coesão de cada unidade (movimento) do texto e que estabelecem simultaneamente sua própria ligação e a unidade do conjunto. Unidade que não significa aqui nem linearidade nem fechamento, mas aquilo que dá consistência material a esse texto em espiral, cuja dinâmica só se cristaliza no espaço de uma leitura.

Por fim, esta análise permite esclarecer às avessas o processo crítico operado por uma tradução do tipo literal, tomada no sentido moderno do termo: uma tradução em que perda e ganho se equilibram à medida que todos os parâmetros do texto são levados em conta no processo tradutório.*

A afirmação de Jacques Roubaud segundo a qual a literatura é código formal e memória semântica de uma língua adquire uma nova dimensão nesse espaço galáctico. O texto de Haroldo de Campos codifica e transforma os dados prosódicos e sêmicos da língua (retransformados por nossa tradução). E ele os transforma fazendo explodir os limites dessa língua ao integrar nos mesmos paradigmas uma série de neologismos e/ ou palavras-valises de outros idiomas, tornando assim patente que a fusão se faz num nível linguístico profundo (inconsciente) mas no ritmo do discurso.

Segunda parte:

O texto como teoria do texto e como saber da literatura

A segunda parte da nossa análise-leitura tem como objetivo não mais o texto como objeto semiótico (poético) em si, mas sua inserção no contexto histórico-literário, o que significa dizer, sua inserção, por um lado, na tradição e, por outro, na intertextualidade. Essa interpretação é evidentemente informada pela análise precedente. $^{10}$

\footnotetext{
${ }^{10}$ Que corresponde ao comentário do processo de tradução e à verificação das
}

* (Ver OSEKI-DÉPRÉ, Inês. Théories et Pratiques de la Traduction Littéraire. Armand Colin, Coll. U, Paris, 1999, em particular o capítulo dedicado às teorias prospectivas.) 
Examinaremos, pois, em primeiro lugar, a maneira como o texto original (referindo-nos apenas ao texto traduzido) contém sua própria teoria e, em seguida, em que medida ele busca transformar a literatura e a realidade.

A metalinguagem

Retomemos o início do poema, que chamaremos de Introdução ou Introito:

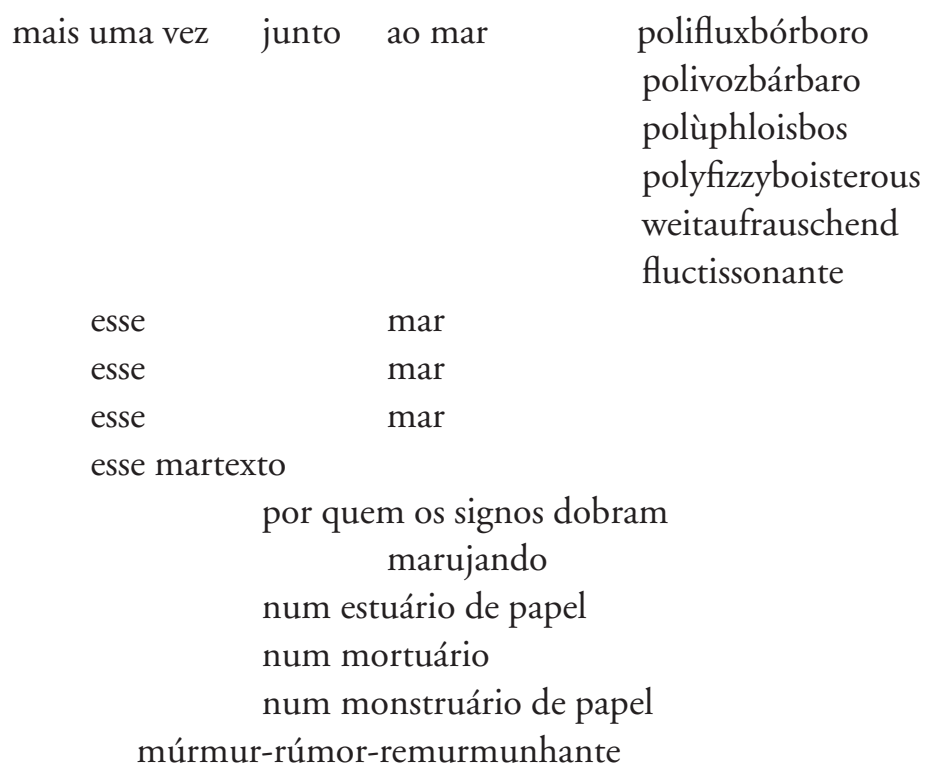

une fois de plus vers la mer

polifluxborborante polivocobarbare polùphloisbos polyfizzyboisterous weitaufrauschend fluctissonante

$\begin{array}{ll}\text { vers } & \text { la mer } \\ \text { vers } & \text { la mer } \\ \text { cette } & \text { mertexte }\end{array}$

pour qui consonnent les glas cette mer matelottante dans son estuaire de papier 
Aqui verificamos inúmeras equivalências fonossemânticas paradigmáticas, justapostas sobre o eixo sintagmático, e que explicitam a metalinguagem. Além disso, algumas observações se impõem no que diz respeito tanto ao número de sílabas, bem regular, dos determinantes de "mer" (6, 6, 5, 7, 4 e 4), quanto ao significado invariante e seu significante poliglota e homófono, em um funcionamento par (similar).

A mesma equivalência é encontrada nas recorrências "vers la mer" e no complemento circunstancial de lugar que segue "matelottante", constituído por uma enumeração amplificante ("estuaire de papier", "mortuairemonstruaire de papier"). A sequência "murmurrumeur-ruante", que dá a rima a "fluctissonante" e a "matelottante" segue o caminho inverso - pois começa com uma meia palavra, prossegue com uma palavra plena que a alitera (e de certa forma a anagramatiza), e termina com a palavra "ruante", que a completa acrescentando-lhe um sentido ativo (verbal). A tradução, bastante literal no conjunto, substitui, contudo, "remurmunhante" por "ruante", em uma homenagem não gratuita à "nixe" do "Soneto em yx" mallarmeano. O motivo do "mar" é, como veremos em seguida, essencial (o mar de papel).

\section{Um sujeito não lírico}

Como vimos anteriormente, o texto se dirige a um "você" desde o Introito. Ora, "você" é o sujeito, extremamente ambíguo, dessa parte, e pode designar tanto você-leitor quanto você-que-escreve (as duas instâncias sendo intencionalmente confundidas e reciprocamente identificáveis). E como bem sabemos desde Benveniste, no momento em que um "você" se apresenta, fica pressuposta a presença da instância de um "eu”, sujeito da enunciação.

"Você" coloca aqui a questão da enunciação no ato da palavra-escritura. $\mathrm{O}$ texto se situa, assim, no nível do discurso e não no do enunciado, que, sob a falsa noção de objetividade, é aquilo que se pretende mais próximo da "verdade", ao passo que, na ficção ${ }^{11}$,

${ }^{11}$ Haroldo de Campos evoca Wolfgang Iser, que, em "Akte des Fingierens", associa ficção e linguagem. Para a tradição da poesia, essa relação nunca deixou de ser estreita. "Poeta ---poetas: es quier dezir tanto como fallador de nuevo de razón, e enfennidor dela...” Essa definição da função do poeta na General Estoria do rei- 
* (linha 3)

* (linhas 6-7)

* (linhas 5-6)

* (linha 7)

* (linha 7)

* (linha 8)

* (linha 9)

* (linha 12)

* (linha 30)

* (linha 38)

* (linha 40)

a única verdade reside no tecido discursivo que se deixa surpreender ou se revela ao enunciar-se no próprio ato da escrita. Esse mecanismo se confirma pela presença massiva dos dêiticos anteriormente referidos ("ces", "tes", "ta").

O sujeito da enunciação permanece pressuposto no emissor (" $t u$ "), mas sobretudo nas formas dêiticas da primeira pessoa, ao longo de todo o texto. No fim (terceiro movimento), ele se torna explícito sob a forma "je veux", que indica não apenas a presença do sujeito enunciador como também a concomitância do dizer e da ação (performativo): ao dizer "je veux", eu ajo.

Assim, do "je" implícito de "cette mer"*, "toi-tu”*, "ces (signes)"*, "tes (ruines)"*, "ces (signes-sons)”*, "ton (fieldorado)”*, "ta (mortépopée)"*, "maintenant”, "ce (texte)"*, "ça”, "ici”*, chegamos ao "je" explícito de "je veux". No entanto, a frase final vota o texto ao anonimato, à pessoa ausente ("elle"), e exclui, ao conduzir o texto ao seu termo, sua apropriação por um " $j e$ ”. Veremos mais adiante que essa não apropriação, ressaltada por um jogo aparentemente enunciativo - mas acima de tudo metalinguístico -, assume a forma de uma citação intertextual.

Ao mesmo tempo, o primeiro movimento introduz a não pessoa, "elle", objeto do qual se fala no texto. Esse embrião de ficção, cuja tonalidade sêmica é erótica, vem dissolver-se e desaparecer ("la même châtain-lisse main") no ato de escrever, na máquina de escrever.

A sequência, ao nível da oração coordenada introduzida por "car" (terceiro paradigma), marca uma nova cena da escrita: o retorno do sujeito implícito, mas, sobretudo, a insistência de uma lucidez metalinguística e quase teórica em relação à atividade produtiva da prática significante: "car les glas consonnent pour ce texte qui subsume les contextes et les produit comme figures d'écriture...".

O segundo movimento reintroduz "elle" que, por sua vez, reaparecerá no Final, sempre no mesmo contexto:

"dans la... position" (primeira, segunda, terceira...)

"Elle" - misteriosa - posta em cena/ posta em signo, passiva e agredida, e que se transforma em signos pela mão (châtain-lisse) do poeta. "Elle”, não a atriz, mas talvez uma atriz no script da memó-

trovador Alfonso, El Sabio (1221-1284) pode ser retomada por quem quiser dar uma espessura diacrônica às ideias tão tipicamente próprias ao corte afiado da modernidade como a do histrião literário de Poe e a do poeta "fingidor" de Pessoa, passando pelo par ficção e fictício: "un tour ou jonglerie (tout Art em est là)..." - na poética de Mallarmé. 
ria, representa o fio tênue da ficção, criada, recriada e consumida no discurso, de acordo com as palavras de Thompson: "Whatever I am talking about, I am also talking about literature". No texto, a referência ao discurso literário é a cada vez explicitada:

"un texte dactyloécrit...trace" (I)

"dire que ces mots..." (II)

"elle est signe..." (III).

O terceiro paradigma (presente nos três movimentos) apresenta a particularidade, já mencionada, de esclarecer o texto, de situá-lo em um nível mais teórico. Com efeito, podemos "traduzir" as três orações:

I- car les glas consonnent

II- car le langage est lavage

\section{III- car il ne s'agit pas ici d'un livre-rose}

da seguinte maneira: os signos, convertidos por "toi-je" (você-eu) em sinos que dobram; ela, signo, convertido por "toi-je" (você-eu), dobra, mas os signos-sinos dobram pelos signos-sons convertidos por "toi-je" (você-eu). A alusão ao aspecto fúnebre do verso implícito de John Donne desaparece aqui, certamente, em favor da paronomásia "consonner" que não tem essa conotação em francês.

Em outros termos, a linguagem é a memória e, justamente por isso, é o lugar de coexistência de lama, detrito, cloaca. Não obstante, o trabalho sobre a matéria significante se apresenta como o único ato capaz de "lavar" a linguagem, de esvaziá-la da "civilização" e de apagar as palavras inúteis criando outras e conservando os traços do mar de Homero, vogais e consoantes.

A última oração define o livro - pois as Galáxias são o livro: um nigrolivro, um pesteseller, um horrídeodigesto, o livro que corrói e recusa o final feliz; mas quem recusa o fim, recusa o início e toda a concepção da literatura tradicional, logocêntrica, assim como a fábula, o Autor, os ingredientes habituais do repertório canônico. Essa última oração se destaca pela estrutura negativa ("il ne s'agit pas ici”) seguida de uma dupla afirmação (“mais bien”). E se, como propõe Jacques Roubaud, a poesia em verso livre anuncia o Círculo linguístico de Praga e o trabalho dos formalistas, a poesia pós-utópica de Haroldo de Campos avança no sentido da disseminação derridiana. 
Resta-nos, ainda, nesta seção, comentar a unidade parentética narrativa, a única a apresentar completamente as aparências formais da ficção.

Já comentamos a relação entre as unidades:

dans la... position

I car...

II

na qual I e II se apresentam no âmbito de uma concepção teórica da literatura (pós-utópica). ${ }^{12}$

Ora, aqui, ao mesmo tempo em que se apresenta na $3^{\text {a }}$ pessoa ("l'histoire de l'allemand"), como em I e II, o sujeito se opõe às outras unidades por estar negativamente marcado do ponto de vista semântico. Trata-se de um "personagem" tolo, o personagem da anedota, pois ele representa o consumidor (o capitalista), a língua (e a concepção de língua como registro acumulável, como um dicionário empoeirado): tantas palavras por mês, por ano, com o objetivo de apoderar-se de um idioma outro. Tal atitude, assim criticada, é a antítese da teoria do Texto, na medida em que este faz falar outras línguas em sua língua.

E isso explica que a relação entre a anedota - formalmente distinta do restante do texto - e a continuação se apresente sob a forma de uma ruptura: "je veux qu'elles se fassent foutre" ("quero que se danem").

No conjunto, o texto, caracterizado pela recorrência, pela manutenção e pela transformação cíclica de suas unidades, oferece uma teoria da prática literária (escrita e tradução) amparada pelo jogo das pessoas que lhe servem de fio condutor.

O sujeito pressuposto, o sujeito enunciador, se oculta, mas revela sua ocultação ao deixar-se investir pela dialética lúdica (aporética?) dos diversos pronomes na distribuição que se segue:

\footnotetext{
${ }^{12}$ Termo que Haroldo de Campos prefere a "pós-moderno" na medida em que corresponde a um momento da História. Esse momento é o da perda da Esperança revolucionária que funcionava como o motor ideológico de uma revolução formal. O pós-utópico não configura uma recusa da ação mas a proposta de uma ação diferente. Ver "Pós-tudo", poema de Augusto de Campos. Cf. Augusto de Campos e Haroldo de Campos. "Poesia e modernidade". O arco-íris branco. Rio de Janeiro: Imago, 1998.
} 


\begin{tabular}{lll} 
toi & cette & \multicolumn{1}{c}{ elle } \\
tu & ces & (associada à prática) \\
tes & $c e$ & les glas-signes- \\
ton & ça & vagissement-main- \\
ta & je & la salive-texte- \\
& ici & homère-faune-le \\
& maintenant & langage-la toile- \\
& & tout-le cauchemar-
\end{tabular}

VEUX

\author{
l'histoire de allemand \\ (associada à concepção \\ negativa da língua \\ como depósito de \\ palavras)
}

\author{
$\mathrm{O}$ \\ (anulação do sujeito \\ no Texto)
}

\title{
Tradição e intertextualidade
}

(a) O itinerário percorrido pelo sujeito, que engloba (como Lautréamont) o leitor em sua prática por meio do pélago-linguagem, mar em que a velha cultura do capitalismo linguístico (pela mediação do estrangeiro) se afoga na produção significante, faz aparecer uma presença feminina tão fictícia quanto difusa e o que resta é o texto em sua enunciação, por meio da qual um querer (um desejo?) se afirma, em um clarão.

O texto participa, assim, dos traços que, pelo fato de contemporâneos, não negam a própria história. Traços de uma escrita que engendra sua própria teoria, nova teoria da linguagem-pensamento. A literatura (a poesia) prossegue na via da transformação das velhas estruturas, anulando com esse gesto o sujeito enquanto

\footnotetext{
13 "Teoria" remete aos elementos metalinguísticos da oração; "Prática" à presença do sujeito e "Ficção" aos elementos da fábula.
} 
consciência suprema (logocêntrica), senhor de seus personagens e de suas fábulas.

Essa desapropriação do discurso se manifesta igualmente por meio de uma trama de citações, assim "pour qui (con-) sonnent les glas" é a alusão ao verso de John Donne ("From whom the bells toll'), também já reutilizado por Hemingway em seu romance e, mais tarde, resgatado por Hollywood (o que cria o elo com a definição do "livro"). Da mesma forma, "ces signes tu les dresses contre tes ruines ou tes ruines contre ces signes-sons" é a citação parafrástica do verso de Eliot (final do The Waste Land): "These fragments I have shored against um ruins", a que Ezra Pound contrapõe (Canto VIII): "These fragments you have shelved (shored)".

(b) Simultaneamente esboça-se uma outra encenação da intertextualidade pela via da tradução. "Poliparole" designa "polùphloisbos", de Homero, mas inclui a literatura em seu processo histórico e em seu devir de "traductions voyelles vogantes contre le jaillissement mobile des consonnes". Além disso, essa palavra homérica funciona como a pedra de toque do texto - Ezra Pound (que a reutiliza em suas poéticas e críticas) -, por meio do paradigma parafônico que ele ali induz, e também das traduçóes de Joyce ("polyfizzyboisterous"), de Voss ("weitaufrauschend") e do brasileiro Odorico Mendes ("Aluctissonante") ${ }^{14}$ : todas transcrições ${ }^{15}$ poéticas. O que quer dizer que o texto também traz em si uma teoria da tradução como meio (instrumento) poético.

Assim, "poliparole" retoma a série de epítetos do mar homérico e a série "voyelles vogantes", "voyage revoyage le long d'un livrede-voyage", reporta-se a outros textos de Galáxias, como em um único sopro.

As mesmas recorrências são encontradas no segundo movimento, em configuração quiasmática, produzidas por meio de uma tentativa de transcriação:

"urna água de barrela uma borra de baixela"

"une eau de lessive une lie de vaisselle",

na qual verificamos a presença das mesmas sonoridades invertidas.

\footnotetext{
${ }^{14}$ Odorico Mendes é autor, entre outros, de uma versão da Odisseia particularmente trabalhada do ponto de vista da prosódia. Haroldo de Campos dedicou a ele vários estudos.

${ }^{15}$ A esse propósito, ver Haroldo de Campos. "De la traduction comme création et comme critique". Transformer traduire. Change, $\mathrm{n}^{\circ} 14$. Seghers/Laffont, février 1973.
} 
As rimas e ecos sobejam nos trechos:

"a tela se entretela à tela"

"la toile s'entretoile à la toile"

"charonhas carantonhas ou carantelas que trelam e taramelam"

"des trognes des charognes qui trichent et trébuchent".

A última frase é particularmente difícil de traduzir: nela poderíamos acrescentar "des tronches" para carantonhas, e também encontramos neologismos como "trelam" (de "trela", em "dar trela a": mostrar-se familiar), ao lado de palavras que existem mas que são raramente encontradas.

O mesmo tipo de configuração fonoprosódica se encontra em "pois a linguagem é lavagem é resíduo de drenagem" (linhas 27 28) ("car le langage est lavage est résidu du drainage") e em "é ressaca e cloaca" (linha 28) "est ressac et est cloaque", à qual se acrescenta a interposição que se verifica em "toile s'entretoile" e que se repete em "nuit nuisible". "Message" e "langage" respondem a "car le langage"... mas também a "voyage revoyage...". Note-se ainda a configuração aliterante de: "surexcès", "abcès", "obsexionnê" ("excessos”, "abcessos", "obsessos").

(c) O texto como questionamento da realidade.

É difícil isolar esse fragmento do conjunto de Galáxias, e éainda mais difícil isolar Galáxias do projeto global de Haroldo de Campos. Iniciado em 1963, no auge do período de Esperança (o grupo Noigandres, 1955; Brasília e o Plano-Piloto, 1962, ano da grande efervescência política e cultural no Brasil), a obra (diário de viagem?) continuou a ser escrita até 1976 . O fragmento analisado data de 1970, momento de endurecimento da ditadura militar no Brasil, de tendência neofascista. Pode-se ler na obra certa desesperança, para a qual a consolação permanece como o poien, o fazer ("porque é mais difícil do que não fazer”, João Cabral de Melo Neto).

Não podemos, portanto, nos contentar com uma leitura semiótica que se limite a confirmar o pertencimento do texto ao domínio poético, ainda que como um tributo à literatura, imbricado em uma convocação / denúncia da realidade. Na verdade, o projeto Galáxias é muito mais amplo, uma vez que religa o antigo e o novo, mas, sobretudo, porque propõe uma nova leitura $e$ da literatura $e$ da realidade.

Nesse ponto, falamos de uma escrita barroca a seu respeito, o que não encontraríamos dificuldade para demonstrar caso definíssemos o barroco por meio da afluência (concentrada) de pala- 
* (CAMPOS, Haroldo de. "De la raison anthropophagique". Lettre internationale, $\mathrm{n}^{\circ} 20$ (printemps 1989) e $O$ sequestro do barroCo, Fundação Casa de Jorge Amado,Salvador, Brasil, 1989.)

*(PESSOA, Fernando. "Mensagem" Obra Poética. Rio de Janeiro, Nova Aguilar, 1965.) vras rebuscadas, pela antítese entre alto e baixo e, sobretudo, pelo sopro. Decerto que Haroldo de Campos faz alusão ao barroco, mas muito mais como um lamento (um motivo) do que como uma forma de escrita. E se quiséssemos interpretar a expressão "tua barrouca mortopopeia ibericaña" (...) poderíamos levar em consideração tanto "barrouca" quanto "mortopopeia".

Pois, para o poeta brasileiro, contrariamente às ideias feitas a respeito da cultura nacional (que seria uma subcultura portuguesa tentando afirmar seu nacionalismo somente a partir do século XIX), o pais nasceu barroco: "eu diria que, para nós, o barroco é a não origem: nossas literaturas, que fizeram sua aparição com o barroco, não tiveram infância (infans: aquele que não fala). Elas nasceram adultas (como certos heróis da mitologia), falando um código universal extremamente elaborado: o código retórico barroco (com resquícios da Idade Média tardia e do Renascimento, depurados, no caso brasileiro, pelo maneirismo de Camões)".* Mas, desde então, essa epopeia barroca está morta.

Em compensação, são inúmeras as referências à epopeia, primeiramente de forma explícita ("uma palavra-búzio que Homero soprou e que se deixa transsoprar"), em seguida de forma intertextual. Aludimos acima às homenagens prestadas a poetas de língua inglesa citados no fragmento tais como John Donne, T. S. Eliot e Ezra Pound. Encontramos igualmente uma reverência tácita a Mallarmé e outra menos tácita a Fernando Pessoa, poetas que Haroldo aproxima pela relação deles com a ficção. Fernando Pessoa é o autor de um poema Ulisses, mito "que é o nada que é tudo", sobre aquele que "sem existir nos bastou e nos criou".* E que poderíamos indexar como a origem da literatura.

Para Ezra Pound, trata-se de fazer como Homero, de escrever a epopeia de um homem moderno partindo de Homero ${ }^{16}$ e de ser, ao traçar seu itinerário no tempo (Homero, Propércio, Di Cavalcanti, Dante, os trovadores), o "ministro das artes sem pasta" (Horace Gregory), uma espécie de porta-voz do homem ocidental ("antena da raça”).

Ora, se Ezra Pound é nominalmente citado como tradutor (e reanimador) do passado, nossa tradução (enquanto instrumento crítico, enquanto leitura aproximada), nos permite apreender um outro parâmetro do texto haroldiano, e não podemos deixar de mencionar Joyce. O que é interessante é o fato de que o próprio

\footnotetext{
${ }^{16}$ Ver os Cantos d'Ezra Pound, que integram os fragmentos de Homero.
} 
Haroldo de Campos preconiza o método "ideogrâmico" recomendado por Ezra Pound e que consiste em estimar a relação ("influência”) entre duas escritas via tradução.* Aqui, nos encontramos não somente diante da alusão a uma koinè comum, à viagem de Ulisses - que em Joyce é uma viagem interior -, como também frente a um projeto poético em todos os sentidos da palavra: as origens da narrativa, as origens da poesia e também os procedimentos joycianos que relatam essa origem, as palavras bárbaras, os neologismos, as palavras-valises, a citação, a justaposição, o fora e o dentro, a ironia na frase infinita. Ao mesmo tempo, trata-se, no caso do poema, de reunir Pound e Joyce, estes dois gigantes da poesia que foram tão próximos e tão distantes. ${ }^{17}$

Segundo Forrest Read, "Pound e Joyce foram os únicos que decidiram, desde o inicio, seguir a vocação clássica e preparar-se para escrever uma epopeia (...) como modernos e como clássicos". "Ambos aprimoraram uma ideia única visando uma forma sintética, cada vez mais ampla, mais abrangente”, e Pound chegará ao ponto de dizer: "Ulysses é a minha resposta".*

Assim, a referência ao barroco ${ }^{18}$ faz parte desta intenção propedêutica: o poema pós-utópico é a reescrita de Homero (via tradução de Odorico Mendes, via hipertradução de Joyce, via intertradução de Pound), homenagem à tradição e devir.

\section{Conclusão}

Seria possível concluir assim também com relação a Haroldo de Campos, ${ }^{19}$ mas não sem atentar para certas considerações que ele tece em seu prefácio à sua tradução do Finnegans Wake: "O ritmo desta prosapoesia - riverrun-ricorrente - é qualquer coisa como um fluxo global e contínuo. Élan-vital. Durchdringung... Uma tex-

\footnotetext{
${ }^{17}$ Sabe-se tudo que Joyce deve a Pound pelo reconhecimento de sua obra. São inúmeros os artigos e intervenções (inclusive de ordem financeira) deste último junto a editoras, revistas e pessoas importante (Yeats, Eliot). Sabe-se também a que ponto Pound via em Joyce um gênio sem, contudo, aderir inteiramente a sua obra.

${ }^{18}$ Sobre o Ulisses de Joyce, Pound diz: "Nós encontramos ali Telêmaco, seu pai, as sereias, o Ciclope, sob disfarces inesperados, barrocos, argóticos, verídicos e gigantescos". Pound/ Joyce . Paris: Mercure de France, 1970: 228.

${ }^{19}$ O que é confirmado por um poema bem mais recente (1990), no qual a identificação com o Ulisses de Dante é mais clara, a hybris do poeta-viajante o conduz ao inferno. Ver "Finismundo: a Última Viagem". Os melhores poemas de Haroldo de Campos. Seleção de Inês Oseki-Dépré. São Paulo: Global, 1992. Traduzido por Inês Oseki-Dépré para o Festival de poesia do Vale do Marne, em 1995 , e publicado em Une anthologie immédiate (Paris: Fourbis, 1996).
}

* (CAMPOS, Haroldo de. "De la raison anthropophagique". op. cit: 81.)

* (READ, Forrest. Pound) Joyce: The Letters of Ezra Pound to James Joyce, with Pound's Essays on Joyce. New Directions, 1967: 17.) 
* (CAMPOS, Haroldo de \& CAMPOS, Augusto de. Panorama do Finnegans Wake. São Paulo: Perspectiva, 1971: 23.)
Palavras-chave: Haroldo de Campos; tradução; intertextualidade; barroco. tura onde a noção de desenvolvimento linear da narrativa deixa de ser válida. Tudo se passa em um tempo total e em um espaço total. Espaçotempo. $\mathrm{O}$ verdadeiro personagem é a linguagem.”

Poderíamos parodiar Voltaire, citado por Jacques Delille, tradutor de Eneida, outro hipertexto da epopeia homérica: "Se foi Homero quem fez Virgílio, foi sua mais bela obra." Com efeito, se foi Homero quem fez Pound, Joyce, Pessoa, Haroldo de Campos, foram suas mais belas obras, com a diferença que, para o poeta brasileiro, Ulisses não é um personagem, mas o próprio poeta. ${ }^{20}$

Tradução de Andréa Taboada

Revisão da autora.

\section{Inês Oseki-Dépré}

Nasceu em São Paulo e fez seus estudos na USP. Hoje é professora titular na Universidade de Provença onde introduziu um master em tradução literária. Traduz do francês para o português (Os Escritos, de Jacques Lacan, 1972; Algo: Preto, de Jacques Roubaud, 2006), mas principalmente do português para o francês (Guimarães Rosa, José de Alencar, Antonio Vieira, Fernando Pessoa, Carlos Drummond de Andrade, João Cabral de Melo Neto, Haroldo de Campos, Augusto de Campos, Décio Pignatari, entre vários outros...). Tradutora da integralidade das Galáxias de Haroldo de Campos (prêmio Roger Caillois da melhor obra poética estrangeira publicada na França em 1999), verteu recentemente para o francês uma constelação de poetas novos brasileiros. Como pesquisadora, é autora de ensaios no Brasil e na França. Seu livro Théories e pratiques de la traduction littéraire (1999, reedição em 2006) conhece um grande sucesso.

\section{Resumo}

Este artigo examina o fragmento 45 das Galáxias de Haroldo de Campos em sua tradução francesa considerada como texto original. Na primeira parte, a autora interroga o aspecto meteórico do texto no intuito de demonstrar de que maneira o poema é ao mesmo tempo memória e devir da língua. Em um segundo momento, a questão da intertextualidade latente no fragmento é abordada como um saber sobre a literatura. Trata-se de mostrar, por meio

\footnotetext{
${ }^{20} \mathrm{O}$ que, segundo os termos de Pound, o incluiria na categoria "fálica" e logo poética - movida pelo desejo -, e não "escatológica" e portanto narradora, movida pela análise, e na qual ele coloca Joyce.
} 
de uma análise da aporia da tradução, que se o texto traz consigo um saber sobre a literatura, ele também comporta outros elementos cognitivos a serem decodificados em sua recepção. A escrita haroldiana é assim apreendida em sua reapropriação das estruturas barrocas.

\section{Abstract}

This article examines fragment 45 of Haroldo de Campos' Galaxies in its French translation considered to be the original text. The author first questions the meteoric side of the text in order to demonstrate how language, in the poem, is at once memory and its state of becoming. The author goes on to question the latent intertextuality in the fragment, seen as knowledge of literature. We see that by way of an analysis of the aporia of translation, that if the text deals with this knowledge of literature, it contains other cognitive elements to be decoded upon the text's reception. Haroldean writing is thus understood in its reappropriation of its baroque structure.

\section{Résumé}

Cet article porte sur le fragment 45 des Galaxies de Haroldo de Campos dans sa traduction française considérée comme texte original. Dans la première partie, l'auteure interroge l'aspect météorique du texte afin de démontrer de quelle façon le poème est à la fois mémoire et devenir de la langue. Dans un deuxième temps, la question de l'intertextualité latente dans le fragment est abordée comme savoir sur la littérature. Il s'agit de montrer, à travers une analyse de l'aporie de la traduction, que si le texte porte un savoir sur la littérature, il comporte d'autres éléments cognitifs à décoder lors de sa réception. L'écriture haroldéenne est ainsi appréhendée dans sa réappropriation des structures baroques.
Keywords: Haroldo de Campos; translation; intertextuality; baroque.

Mots-clés: Haroldo de Campos; traduction; intertextualité; baroque.
Recebido em 15/02/2011

Aprovado em 15/04/2011 